\title{
Invasive and non-invasive diagnostic approaches for microbiological diagnosis of hospital-acquired pneumonia
}

\author{
Otavio T. Ranzani ${ }^{1,2+}$, Tarek Senussi ${ }^{1,3+}$, Francesco Idone ${ }^{1,4}$, Adrian Ceccato ${ }^{1,5}$, Gianluigi Li Bassi ${ }^{1}$, Miquel Ferrer ${ }^{1}$ \\ and Antoni Torres ${ }^{1 *}$
}

\begin{abstract}
Background: Data on the methods used for microbiological diagnosis of hospital-acquired pneumonia (HAP) are mainly extrapolated from ventilator-associated pneumonia. HAP poses additional challenges for respiratory sampling, and the utility of sputum or distal sampling in HAP has not been comprehensively evaluated, particularly in HAP admitted to the ICU.
\end{abstract}

Methods: We analyzed 200 patients with HAP from six ICUs in a teaching hospital in Barcelona, Spain. The respiratory sampling methods used were divided into non-invasive [sputum and endotracheal aspirate (EAT)] and invasive [fiberopticbronchoscopy aspirate (FBAS), and bronchoalveolar lavage (BAL)].

Results: A median of three diagnostic methods were applied [range 2-4]. At least one respiratory sampling method was applied in 93\% of patients, and two or more were applied in 40\%. Microbiological diagnosis was achieved in 99 (50\%) patients, 69 (70\%) by only one method (42\% FBAS, 23\% EAT, 15\% sputum, 9\% BAL, 7\% blood culture, and 4\% urinary antigen). Seventy-eight (39\%) patients underwent a fiberoptic-bronchoscopy when not receiving mechanical ventilation. Higher rates of microbiological diagnosis were observed in the invasive group (56 vs. 39\%, $p=0.018$ ). Patients with microbiological diagnosis more frequently presented changes in their empirical antibiotic scheme, mainly de-escalation.

Conclusions: A comprehensive approach might be undertaken for microbiological diagnosis in critically ill nonventilated HAP. Sputum sampling determined one third of microbiological diagnosis in HAP patients who were not subsequently intubated. Invasive methods were associated with higher rates of microbiological diagnosis.

Keywords: Hospital-acquired pneumonia, Microbiological diagnosis, Diagnostic methods, Hospital infections, Bronchoalveolar lavage

\section{Introduction}

Hospital-acquired pneumonia (HAP) is a frequent event during an intensive care unit (ICU) stay and is characterized by a pneumonia acquired during hospitalization, in patients without invasive mechanical ventilation [1-3]. Despite improved prevention measures, antimicrobial therapy, and supportive care, it remains an important

\footnotetext{
*Correspondence: atorres@clinic.cat; https://www.idibapsrespiratoryresearch. org/

${ }^{\dagger}$ Otavio T. Ranzani and Tarek Senussi contributed equally to this work. 'Department of Pneumology, Institut Clinic de Respiratori, Hospital Clinic of Barcelona, Institut d'Investigacions Biomèdiques August Pi i Sunyer (IDIBAPS), University of Barcelona (UB), ICREA Academia award, Ciber de Enfermedades Respiratorias (Ciberes, CB06/06/0028), Barcelona, Spain

Full list of author information is available at the end of the article
}

cause of morbidity and mortality [1-3]. HAP is the leading cause of death among hospital-acquired infections, with estimates of its associated mortality ranging from 20 to $50 \%[2,4-6]$.

Microbiological diagnosis is fundamental for guiding HAP treatment, allowing a targeted, effective antibiotic choice, and reducing the associated impact of ineffective empiric antibiotic regimens or the unnecessary use of broad-spectrum antibiotics [1]. Yet the current understanding of HAP pathogens is based mainly on data derived from ventilator-associated pneumonia (VAP) [7-15]. Although some studies have reported the pathogens in HAP that occur outside the ICU [16-18], there is no systematic description of the diagnostic approaches that

(c) The Author(s). 2019 Open Access This article is distributed under the terms of the Creative Commons Attribution 4.0 International License (http://creativecommons.org/licenses/by/4.0/), which permits unrestricted use, distribution, and 
should be used to efficiently obtain an microbiological diagnosis in HAP, mainly when critically ill [1].

In comparison with VAP, HAP poses additional challenges for respiratory sampling and, thus, for obtaining microbiological diagnosis. The utility of sputum cultures or distal sampling for HAP has not been comprehensively evaluated [1]. The recent guidelines for HAP/VAP recognized that for some patients, whom non-invasively sampling is not possible, invasive sampling is an option $[1,3]$; however, the literature is scarce to support one method over the other in HAP. In this study, we aimed to describe the diagnostic approaches used in a cohort of HAP acquired during an ICU stay and their associated clinical impact.

\section{Materials and methods Study population}

We conducted a retrospective analysis of a prospective cohort including patients from six medical and surgical ICUs at an 800-bed teaching hospital in Spain. Patients older than 18 years admitted to these ICUs for $48 \mathrm{~h}$ or more with clinical suspicion of HAP or VAP were prospectively and consecutively included. Patients with severe immunosuppression (neutropenia after chemotherapy or hematopoietic transplant, drug-induced immune suppression in solid-organ transplant or cytotoxic therapy, and HIV-infected patients) were excluded. The institution's internal review board approved the study (Comite Etic d'Investigacio Clinica, registry number 2009/5427), and written informed consent was obtained from patients or their next of kin.

\section{Definition of pneumonia}

Clinical suspicion of pneumonia was based on clinical criteria as suggested in the guidelines [1, 5, 19]: (1) new or progressive radiologic pulmonary infiltrate, (2) together with at least two of the following: temperature $>38^{\circ} \mathrm{C}$ or $<36^{\circ} \mathrm{C}$, leukocytosis $>12,000 / \mathrm{mm}^{3}$ or leukopenia $<4000 /$ $\mathrm{mm}^{3}$, or purulent respiratory secretions. HAP was defined in patients who developed pneumonia after $48 \mathrm{~h}$ of hospitalization when not receiving invasive mechanical ventilation (iMV) $[1,20]$.

\section{Data collection}

All relevant data were collected upon ICU admission and at the onset of pneumonia from the medical records and bedside flow charts, including clinical, laboratory, radiological, and microbiological information. Patients' follow-up was extended to death, to hospital discharge, or up to 90 days after the diagnosis of pneumonia. The assessment of severity included the Acute Physiology and Chronic Health Evaluation (APACHE)-II [21] and the Sequential Organ Failure Assessment (SOFA) score
[22], calculated upon ICU admission and at HAP diagnosis.

\section{Microbiologic assessment and methods}

We tried to assess all patients upon clinical diagnosis of HAP, aiming to establish a microbiological diagnosis. Lower respiratory airway samples that could be collected for quantitative bacterial and fungal cultures were (1) sputum, (2) endotracheal aspirate (EAT), (3) bronchial aspirate through a fiberoptic-bronchoscopy (FBAS), and (4) bronchoalveolar lavage (BAL), blinded or through a fiberoptic-bronchoscopy. Only samples of sputum or tracheal aspirates of high quality (i.e. $<10$ squamous cells and $>25$ leukocytes per optical microscopy field) were processed for culture. Additionally, blood cultures (recommended to all patients) and pleural fluid (if a pleural puncture was indicated) could be collected, as well as urinary antigens of Legionella sp. and Streptococcus pneumoniae (mainly recommended for early-onset HAP). Pathogen identification and susceptibility testing were performed by standard methods [23]. Microbiological diagnosis was defined by the presence of at least one potentially pathogenic microorganism (PPM) in respiratory samples above predefined thresholds (sputum, EAT, FBAS $>10^{5}$ colony-forming units $/ \mathrm{mL}$ or BAL > $10^{4}$, or any count if the patient was receiving a new systemic antibiotic treatment). Blood cultures were considered positive if an alternative cause of bacteremia was ruled out [23].

Polymicrobial pneumonia was defined when more than one PPM was identified as causative agents. The initial empiric antimicrobial treatment was chosen following a local adaptation of the 2005 ATS/IDSA guidelines [5], based on the most frequently isolated pathogens and their patterns of antimicrobial sensitivity at our institution. The empiric antimicrobial treatment was considered appropriate when the isolated pathogens were susceptible in vitro to at least one of the antimicrobials administered. Multi-drug-resistant pathogens were defined based on consensus definition [24].

Antibiotic de-escalation was considered when physicians changed the antibiotic regimen to a narrower spectrum regimen, stopped the coverage for a class of pathogens (e.g., Staphylococcus aureus), or reduced the number of antibiotics prescribed [25-27]. Escalation was considered when physicians introduced a new regimen with broader coverage. We further divided the patients whom the empiric antibiotic scheme was maintained in those that no change was done, and in those whom an additional antibiotic was added to the empiric regimen.

\section{Statistical analysis}

To analyze the diagnostic yield of the sampling method, we divided HAP patients into those who were 
subsequently intubated and those who were not, since in patients under iMV, the airway is easy to reach for lower respiratory sampling collection. We also compared patients who received a fiberoptic-bronchoscopy when undergoing or not undergoing iMV.

Data were presented as numbers (proportions) and as means \pm SD or medians [p25-p75]. Qualitative or categorical variables were compared with the chi-square test or Fisher's exact test, as appropriate. Quantitative continuous variables were compared using the unpaired Student $t$ test, one-way ANOVA, and Mann-Whitney or Kruskal Wallis tests as appropriate. All tests were two-sided, and Stata 13.1 was used for all analyses.

\section{Results}

Of the 488 patients enrolled during the cohort period, we excluded 288 (59\%) patients who were diagnosed with pneumonia while receiving mechanical ventilation (i.e., VAP). Therefore, we analyzed 200 (41\%) patients with HAP.

\section{Patient characteristics}

The main clinical characteristics upon ICU admission and at onset of HAP are shown in Table 1. Mean age was 66 years, and there was a high proportion of males. Approximately one third had a chronic comorbidity. The main cause of ICU admission was acute respiratory failure followed by shock and postoperative status. One hundred twenty-two patients (61\%) required iMV after the onset of HAP (Fig. 1), and 72 (59\%) intubations occurred within $24 \mathrm{~h}$ of diagnosis. The median ICU length of stay was 13 [7-26] days, and $85(43 \%)$ patients died in the hospital. Patients who needed iMV after HAP diagnosis presented higher hospital mortality than those who did not [62 (51\%) vs. 23 (30\%), $p=0.003$ ].

\section{Diagnostic approach}

In the 200 patients with HAP, $89 \%$ underwent at least two methods for microbiological assessment (median 3 [2-4] methods). Patients who required iMV had a higher number of microbiological assessments than those who did not (3 [2-4] vs. $2[2,3], p<0.001$, respectively). Respiratory samples were obtained in 186 (93\%) patients, and at least two respiratory methods were applied in $40 \%$. Blood cultures (79\%), urinary antigen (48\%), and FBAS $(47 \%)$ were the methods most commonly applied to microbiological assessment (Fig. 2, Table 2, and Additional file 1: Table S1). Sputum and BAL were performed in almost one third of patients, while $18 \%$ had pleural liquid cultures. Sputum, EAT, FBAS, and BAL were the methods that obtained the highest proportions of positivity (Fig. 2, Table 2, and Additional file 1: Table S1), followed by pleural liquid, blood culture, and urinary antigen testing.
Table 1 General characteristics of patients with hospitalacquired pneumonia (HAP)

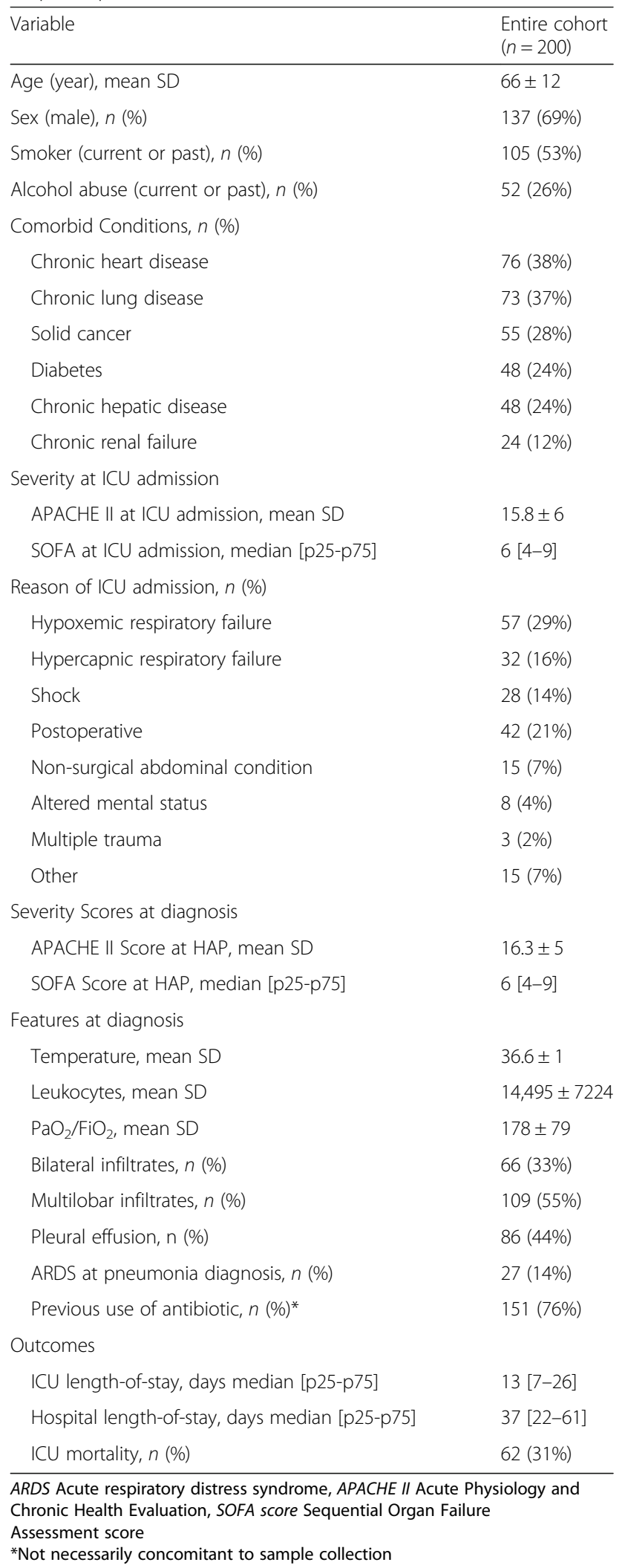




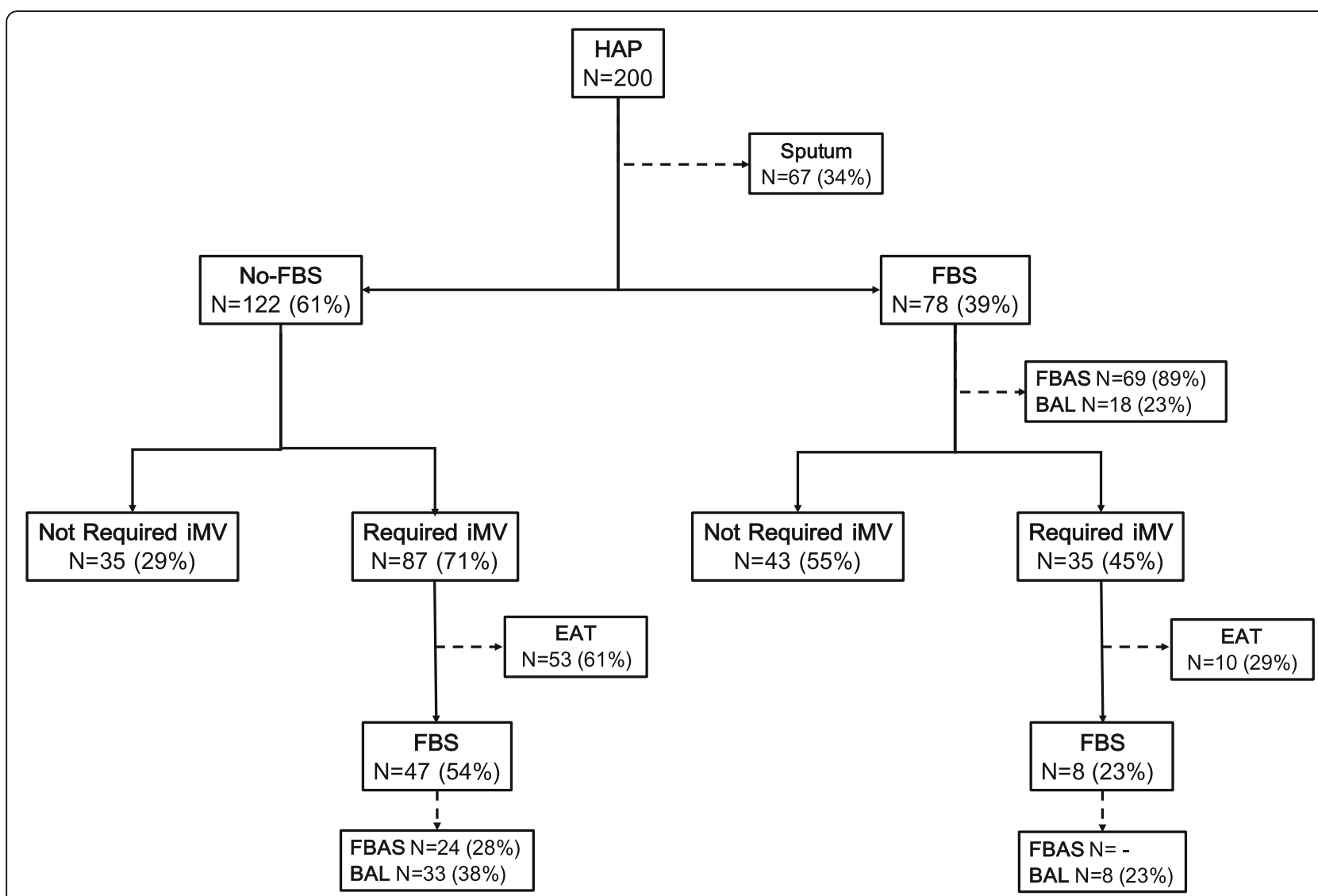

Fig. 1 Time flow-chart for the microbiological assessments performed in 200 patients with hospital-acquired pneumonia. BAL bronchoalveolar lavage, EAT endotracheal aspirate, FBS fiberoptic-bronchoscopy, FBAS fiberoptic-bronchoscopy aspirate, HAP hospital-acquired pneumonia, iMV invasive mechanical ventilation

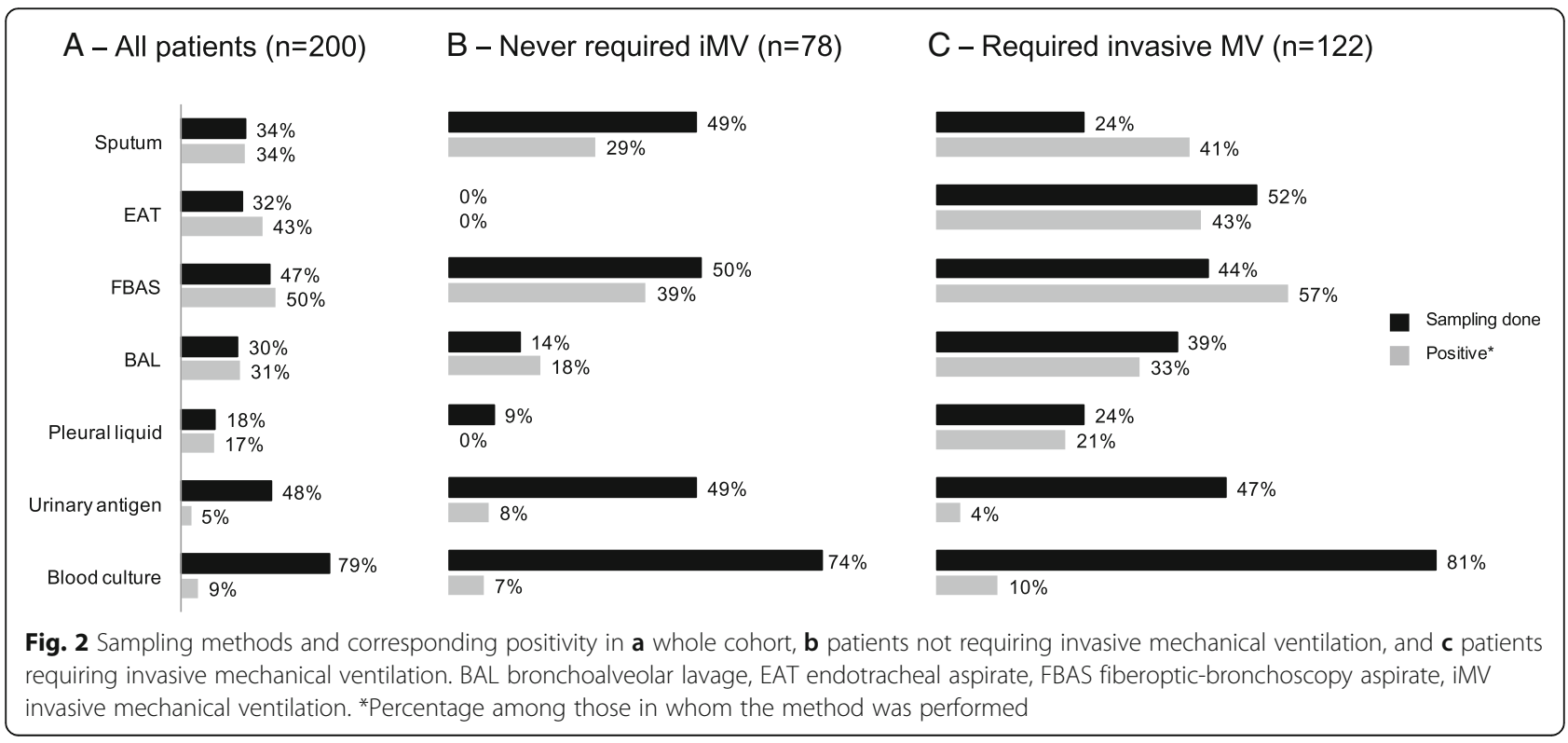


Table 2 Pathogens and contribution of different methods to microbiological diagnosis

\begin{tabular}{|c|c|c|c|c|}
\hline & $\begin{array}{l}\text { Entire cohort } \\
(n=200)\end{array}$ & $\begin{array}{l}\text { Never received invasive } \\
\text { MV after HAP } \\
(n=78)\end{array}$ & $\begin{array}{l}\text { Received invasive } \\
\text { MV after HAP } \\
(n=122)\end{array}$ & $P$ value \\
\hline Definitive causative pathogen & $99(50 \%)$ & $31(40 \%)$ & $68(56 \%)$ & 0.027 \\
\hline Gram negative non-fermenting bacteria & 39/99 (39\%) & $11 / 31(35 \%)$ & 28/68 (41\%) & 0.59 \\
\hline Pseudomonas aeruginosa & 30/99 (30\%) & 10/31 (32\%) & 20/68 (29\%) & 0.78 \\
\hline S. aureus & $24 / 99(24 \%)$ & $6 / 31(19 \%)$ & 18/68 (27\%) & 0.44 \\
\hline MSSA & $15 / 99(15 \%)$ & $4 / 31(13 \%)$ & $11 / 68(16 \%)$ & 0.77 \\
\hline MRSA & 9/99 (9\%) & 2/31 (7\%) & $7 / 68(10 \%)$ & 0.72 \\
\hline Gram negative enteric bacteria & $24 / 99(24 \%)$ & $8 / 31(26 \%)$ & 16/68 (24\%) & 0.81 \\
\hline Community pathogens (S. pneumococcus, Haemophylus influenzae) & 9/99 (9\%) & $3 / 31(10 \%)$ & $6 / 68(9 \%)$ & $>0.99$ \\
\hline Virus & $3 / 99(3 \%)$ & - & $3 / 68(4 \%)$ & 0.55 \\
\hline Other & 9/99 (9\%) & $1 / 31(3 \%)$ & $8 / 68(12 \%)$ & 0.27 \\
\hline Polymicrobial & $17 / 99(17 \%)$ & $3 / 31(10 \%)$ & $14 / 68(21 \%)$ & 0.182 \\
\hline Multi-drug resistant & $40 / 99(40 \%)$ & $12 / 31(39 \%)$ & 28/68 (41\%) & 0.82 \\
\hline \multicolumn{5}{|l|}{ Microbiological diagnosis by } \\
\hline Sputum & 23/99 (23\%) & $11 / 31(36 \%)$ & $12 / 68(18 \%)$ & 0.051 \\
\hline EAT & $27 / 99(27 \%)$ & - & $27 / 68(40 \%)$ & $<0.001$ \\
\hline FBAS & 46/99 (47\%) & 15/31 (48\%) & $31 / 68(46 \%)$ & 0.80 \\
\hline BAL & 18/99 (18\%) & 2/31 (7\%) & 16/68 (24\%) & 0.041 \\
\hline Pleural fluid & 6/99 (6\%) & - & 6/68 (9\%) & 0.051 \\
\hline Urinary antigen & $5 / 99(5 \%)$ & $3 / 31(10 \%)$ & 2/68 (3\%) & 0.175 \\
\hline Blood culture & $14 / 99(14 \%)$ & $4 / 31(13 \%)$ & 10/68 (15\%) & $>0.99$ \\
\hline \multicolumn{5}{|l|}{ Microbiological diagnosis by } \\
\hline 1 method & 69/99 (70\%) & 27/31 (87\%) & $42 / 68(62 \%)$ & 0.015 \\
\hline 2 methods & 20/99 (20\%) & $4 / 31(13 \%)$ & 16/68 (23\%) & \\
\hline 3 methods & 10/99 (10\%) & - & 10/68 (15\%) & \\
\hline \multicolumn{5}{|l|}{ Microbiological diagnosis uniquely defined by 1 method } \\
\hline Sputum & 10/69 (15\%) & $9 / 27(33 \%)$ & $1 / 42(2 \%)$ & 0.001 \\
\hline EAT & $16 / 69(23 \%)$ & - & $16 / 42(38 \%)$ & $<0.001$ \\
\hline FBAS & $29 / 69(42 \%)$ & $12 / 27(44 \%)$ & $17 / 42(41 \%)$ & 0.81 \\
\hline BAL & 6/69 (9\%) & - & $6 / 42(14 \%)$ & 0.075 \\
\hline Pleural fluid & - & - & - & - \\
\hline Urinary antigen & $3 / 69(4 \%)$ & $3 / 27(11 \%)$ & - & 0.056 \\
\hline Blood culture & $5 / 69(7 \%)$ & $3 / 27(11 \%)$ & $2 / 42(5 \%)$ & 0.37 \\
\hline
\end{tabular}

$B A L$ bronchoalveolar lavage, EAT endotracheal aspirate, FBS fiberoptic bronchoscopy, FBAS fiberoptic-bronchoscopy aspirate, HAP hospital-acquired pneumonia, IMV invasive mechanical ventilation

Microbiological diagnosis was possible in 99 (50\%) patients. Patients who required iMV had a higher proportion of microbiological diagnosis than those who did not (56 vs. $40 \%, P=0.027$, Table 2 ). Thirty-eight (19\%) patients received a new antibiotic before sample collection and had a lower proportion of microbiological diagnosis than those who did not ( 34 vs. $53 \%, p=0.036$ ). Overall, the most common pathogens identified were Gram-negative non-fermenting bacteria (39/99, 39\%), followed by Staphylococcus aureus $(24 / 99,24 \%)$ and Gram-negative enteric bacteria $(24 / 99,24 \%)$. The prevalence of polymicrobial HAP was $17 \%$ (17/99), while $40 \%$ had a MDR pathogen. The distribution of causative pathogens was similar in those who required iMV and those who did not (Table 2). The cross-tabulation of different methods for microbiological assessment and their agreement on the same pathogen, when positive, are shown in Fig. 3. The average overall agreement was $80 \%$ 


\begin{tabular}{|c|c|c|c|c|c|c|c|}
\hline \multicolumn{8}{|c|}{ A - Distribution of different diagnostic methods } \\
\hline & Sputum & EAT & FBAS & BAL & $\begin{array}{l}\text { Pleural } \\
\text { liquid }\end{array}$ & $\begin{array}{l}\text { Urinary } \\
\text { antigen }\end{array}$ & $\begin{array}{l}\text { Blood } \\
\text { culture }\end{array}$ \\
\hline Sputum & $\begin{array}{c}67 / 67 \\
(100 \%)\end{array}$ & $\begin{array}{l}16 / 67 \\
(24 \%)\end{array}$ & $\begin{array}{l}26 / 67 \\
(39 \%)\end{array}$ & $\begin{array}{l}15 / 67 \\
(22 \%)\end{array}$ & $\begin{array}{l}10 / 67 \\
(15 \%)\end{array}$ & $\begin{array}{l}34 / 67 \\
(51 \%)\end{array}$ & $\begin{array}{l}49 / 67 \\
(73 \%)\end{array}$ \\
\hline EAT & $\begin{array}{l}16 / 63 \\
(25 \%)\end{array}$ & $\begin{array}{c}63 / 63 \\
(100 \%)\end{array}$ & $\begin{array}{c}7 / 63 \\
(11 \%)\end{array}$ & $\begin{array}{l}22 / 63 \\
(35 \%)\end{array}$ & $\begin{array}{l}15 / 63 \\
(24 \%)\end{array}$ & $\begin{array}{l}27 / 63 \\
(43 \%)\end{array}$ & $\begin{array}{l}52 / 63 \\
(83 \%)\end{array}$ \\
\hline FBAS & $\begin{array}{l}26 / 93 \\
(28 \%)\end{array}$ & $\begin{array}{l}7 / 93 \\
(8 \%)\end{array}$ & $\begin{array}{c}93 / 93 \\
(100 \%)\end{array}$ & $\begin{array}{l}27 / 93 \\
(29 \%)\end{array}$ & $\begin{array}{l}19 / 93 \\
(20 \%)\end{array}$ & $\begin{array}{l}42 / 93 \\
(45 \%)\end{array}$ & $\begin{array}{l}68 / 93 \\
(73 \%)\end{array}$ \\
\hline BAL & $\begin{array}{l}15 / 59 \\
(25 \%)\end{array}$ & $\begin{array}{l}22 / 59 \\
(37 \%)\end{array}$ & $\begin{array}{l}27 / 59 \\
(46 \%)\end{array}$ & $\begin{array}{c}59 / 59 \\
(100 \%)\end{array}$ & $\begin{array}{l}16 / 59 \\
(27 \%)\end{array}$ & $\begin{array}{l}29 / 59 \\
(49 \%)\end{array}$ & $\begin{array}{l}46 / 59 \\
(78 \%)\end{array}$ \\
\hline $\begin{array}{l}\text { Pleural } \\
\text { liquid }\end{array}$ & $\begin{array}{l}10 / 36 \\
(28 \%)\end{array}$ & $\begin{array}{l}15 / 36 \\
(42 \%)\end{array}$ & $\begin{array}{l}19 / 36 \\
(53 \%)\end{array}$ & $\begin{array}{l}16 / 36 \\
(44 \%)\end{array}$ & $\begin{array}{c}36 / 36 \\
(100 \%)\end{array}$ & $\begin{array}{l}17 / 36 \\
(47 \%)\end{array}$ & $\begin{array}{l}31 / 36 \\
(86 \%)\end{array}$ \\
\hline $\begin{array}{l}\text { Urinary } \\
\text { antigen }\end{array}$ & $\begin{array}{l}34 / 95 \\
(36 \%)\end{array}$ & $\begin{array}{l}27 / 95 \\
(28 \%)\end{array}$ & $\begin{array}{l}42 / 95 \\
(44 \%)\end{array}$ & $\begin{array}{l}29 / 95 \\
(31 \%)\end{array}$ & $\begin{array}{l}17 / 95 \\
(18 \%)\end{array}$ & $\begin{array}{c}95 / 95 \\
(100 \%)\end{array}$ & $\begin{array}{l}80 / 95 \\
(84 \%)\end{array}$ \\
\hline $\begin{array}{l}\text { Blood } \\
\text { culture }\end{array}$ & $\begin{array}{l}49 / 157 \\
(31 \%)\end{array}$ & $\begin{array}{l}52 / 157 \\
(33 \%)\end{array}$ & $\begin{array}{c}68 / 157 \\
(43 \%)\end{array}$ & $\begin{array}{l}46 / 157 \\
(29 \%)\end{array}$ & $\begin{array}{l}31 / 157 \\
(20 \%)\end{array}$ & $\begin{array}{l}80 / 157 \\
(51 \%)\end{array}$ & $\begin{array}{c}157 / 157 \\
(100 \%)\end{array}$ \\
\hline
\end{tabular}

\section{B - Agreement on positivity between different diagnostic methods}

Fig. 3 Distribution and agreement of different sampling methods (a cross-tabulation of different methods; $\mathbf{b}$ agreement on the same pathogen when both methods were positive). Square colors divided as dark blue for agreement $\geq 75 \%$, blue for agreement between $\geq 50$ and $<75 \%$, light blue for agreement between $\geq 25$ and $<50 \%$, and grey for agreement $<25 \%$. BAL bronchoalveolar lavage, EAT endotracheal aspirate, FBAS

fiberoptic-bronchoscopy aspirate
(40/50). Indeed, there was $85 \%$ agreement for sputum with other respiratory samples $(11 / 13), 80 \%$ for EAT $(8 /$ $10)$, $81 \%$ for FBAS (13/16), and $91 \%$ for BAL (10/11).

The majority of microbiological diagnoses were determined by only one method (69/99, 70\%), with differences among those who required iMV and those who did not $(p=0.015)$. FBAS was the only method responsible for the diagnosis of $42 \%(29 / 69)$ patients, followed by EAT (23\%), sputum (15\%), BAL (9\%), and blood culture $(7 \%)$.

One hundred twenty-five (63\%) patients underwent invasive sampling, of whom 78 (39\%) were applied fiberoptic-bronchoscopy while not receiving iMV (Fig. 1). Patients who required iMV after invasive sampling were more severe at HAP diagnosis (Additional file 2: Table $\mathrm{S} 2$ ). There was no significant difference in the proportion of final microbiological diagnoses when stratifying by fiberoptic-bronchoscopy when receiving or not receiving $\mathrm{iMV}(p=0.112)$; however, among the patients who did not require $\mathrm{iMV}$, the rate of microbiological diagnosis was $10 \%$ higher ( $95 \% \mathrm{CI},-12$ to $32 \%$ ) in those who underwent fiberoptic-bronchoscopy. When stratifying patients according to non-invasive (sputum and EAT) or invasive (FBAS and BAL) respiratory methods, we observed higher proportions of microbiological diagnoses in those who underwent at least one invasive method (56 vs. $39 \%$, risk difference $17 \%, 95 \%$ CI, 3-31\%, $p=0.018)$, mainly due to those who required iMV.

\section{Antibiotic management and duration}

The majority of patients received the initial antibiotic regimen in accordance with the 2005 ATS/IDSA guidelines; empiric antibiotic treatment was adequate in $71 \%$ (70/99 patients) (Table 3). Patients who had a microbiological diagnosis more frequently changed their empirical antibiotic regimen $(P=0.006)$, driven by deescalation (30 vs. 8\%). However, patients who had a microbiological diagnosis also received longer total antibiotics duration than patients without microbiological diagnosis, although similar duration when considered only the empiric antibiotic scheme.

\section{Discussion}

We could achieve microbiological diagnosis in $50 \%$ of 200 patients with HAP occurring during ICU stay using an intensive diagnostic approach. Upon HAP clinical diagnosis, around $40 \%$ of patients underwent fiberopticbronchoscopy while not receiving iMV. Finally, invasive respiratory sampling was associated with a higher rate of microbiological diagnosis.

Recent recommendations from the FDA recognized that there are three different types of nosocomial pneumonia with different all-cause mortality rates: non-ventilated HAP, ventilated HAP, and VAP [28, 29]. Interestingly, the highest mortality has been observed in patients with HAP who subsequently required iMV. In a recent summary of these recommendations, Talbot 


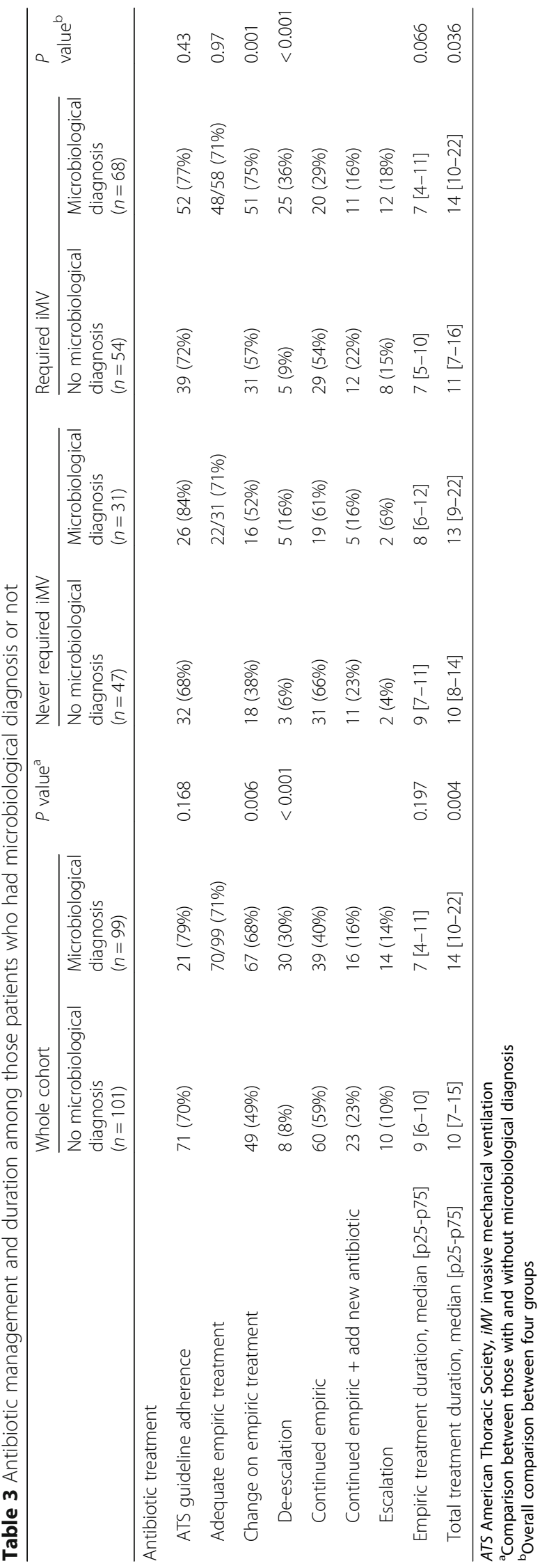


highlighted the necessity to have information about sampling and causative pathogens in the non-VAP population [28]. Our study is the first one to provide this information in a detailed way, which can be very useful for empirical treatment adequacy and for future RCT studying new antibiotics.

Being able to achieve a microbiological diagnosis in HAP has important consequences for patient care. First, it can support the suspicion of infection in a new lung infiltrate appearing concomitantly with fever in a critically ill patient, a frequent challenge for the attending physician [30]. Second, it makes possible to target the empiric antibiotic scheme more accurately, thus increasing the likelihood of clinical cure, preventing the selection pressure to further resistances, and reducing costs and unnecessary side effects [1]. Our findings corroborated two important phenomena reported elsewhere: (1) patients with microbiological diagnosis more commonly had an adaptation in their empiric antibiotic regimen and (2) patients without microbiological diagnosis received shorter total antibiotic treatment [31, 32]. Although a microbiological diagnosis is central in all infections both for epidemiological studies and for bedside care by clinicians, it becomes fundamental for hospital-acquired infections, because of higher probability of resistant pathogens, greater amount of antibiotic use and side effects, and associated costs.

Interestingly, one third of patients underwent sputum collection, which was positive in $34 \%$ of cases after ensuring sample quality and performing quantitative cultures. Very few data are available on the applicability of sputum in HAP $[1,16,17]$. In our experience, this non-invasive diagnostic method should be encouraged, as it already is for community-acquired pneumonia [33]. Indeed, when only one diagnostic method was positive, $15 \%$ of microbiologic confirmations were due to sputum, and in patients who were not subsequently intubated, this proportion was even higher (33\%). Despite the limited numbers of patients allowing for pair-wise comparisons between methods, we observed a good agreement on retrieving the same pathogen $(80 \%$ on average). As expected it was higher for invasive methods (FBAS vs. BAL, 86\% of agreement). In our protocol, we tried to obtain as much as possible respiratory samples to increase the likelihood of identifying a causative pathogen, and the good agreement observed is reassuring. When two methods were discordant, respecting the sample quality check and cutoff values, clinicians interpreted the episode as polymicrobial and treated both pathogens, which is sound in critically ill patients. Taking different respiratory samples also increases the risk of false positives (i.e., colonization). We could not evaluate the actual impact that discordance between methods would have in clinician's decision in a scenario where there would be a hierarchy between methods, for instance.
In this observational study, patients assessed with an invasive diagnostic method had higher rates of microbiological diagnosis. Although there is evidence that invasive and non-invasive approaches have a comparable impact on patient-centered outcomes in VAP [1], no evidence is available for HAP in immunocompetent patients [1]. In fact, the 2016 IDSA/ATS guidelines propose non-invasive respiratory sampling in HAP, although the panel agreed that there may be factors that prompt clinicians to consider invasive sampling [1]. In a small single-center randomized trial aiming to compare invasive and non-invasive approaches in patients with HAP outside the ICU, Herer et al. found that clinical cure rates at 28 days were similar between groups; however, the study was rather exploratory in nature, with several limitations and a small sample size [18].

Because of the barriers to obtaining lower respiratory tract samples in HAP, we cannot straightforwardly extrapolate the evidence from VAP to HAP. Indeed, an invasive approach might have higher clinical utility in HAP, particularly in those patients who will not require iMV. A key point when discussing invasive vs. non-invasive tactics in HAP is the feasibility and safety of performing a fiberoptic-bronchoscopy. Several reports show that fiberoptic-bronchoscopy, followed by BAL or mini-BAL, can be conducted in patients with acute respiratory failure and community- and healthcare-acquired pneumonia and is even safer when non-invasive ventilation and high-flow oxygen therapy are applied [34-39]. In a landmark trial, Azoulay et al. showed that an invasive approach had a similar rate of intubation to a non-invasive approach in non-ventilated, immunosuppressed patients with acute respiratory failure [40].

Invasive mechanical ventilation after HAP diagnosis was commonly needed in our population of critically ill patients, being applied $60 \%$ of the time within $24 \mathrm{~h}$. Despite its clear implications for prognosis, having an endotracheal tube vastly facilitates access to a lower respiratory tract sample using either invasive or non-invasive approaches. The ability to predict which patients will need iMV in the next hours can help guide clinicians faced with the decision of performing a prompt fiberoptic-bronchoscopy or postponing it until after the intubation. The development of a prediction tool is beyond the scope of this study, but we observed that severity, hypoxemia, and chest X-ray patterns were associated with intubation after performing a fiberoptic-bronchoscopy.

Our study has some strengths. We included prospective cases of HAP acquired during an ICU stay from six ICUs. Our center also has a comprehensive clinical decision-making protocol for achieving microbiological diagnosis in lung infections, which means that our data are relevant for the description of microbiological diagnosis in HAP. Moreover, the causative pathogens 
responsible for HAP in our cohort are similar to those reported elsewhere, where Gram-negative bacteria have been implicated in 55\% to $85 \%$ of HAP cases and Gram-positive cocci (particularly Staphylococcus aureus) account for $20 \%$ to $30 \%[7,9-11,13,14,41]$, thus increasing the generalizability of our results. In addition, the results of this study cover an unmet need of knowledge (microbiological diagnosis of HAP) highlighted by the recent IDSA ATS and International guidelines for HAP and VAP $[1,3]$.

However, there are several limitations that must be highlighted. First, our study is retrospective and single-center and, although we collected data from six ICUs with different profiles (from general medical to respiratory and liver units), the single-center characteristic decreases the generalizability of our findings. Second, our study is observational and allowed us for a reliable description of real-life diagnostic methods approaches for achieving microbiological diagnosis in HAP, our primary objective. However, the crude associations found for the potential benefit of invasive methods are exploratory and not causal; a well-designed, controlled randomized trial is now warranted to define the management of HAP regarding the use of invasive or non-invasive methods. Third, we could recruit 200 patients, which limited our ability to explore subgroups and pair-wise comparisons between different methods, but to the best of our knowledge, this is one of the first and largest studies reporting all these different diagnostic methods in critically ill nonventilated HAP [42]. Third, we could not achieve $100 \%$ of respiratory samples in the cohort; however, we believe that $93 \%$ represents a very high proportion of patients, considering the daily care in an ICU. Fourth, our population comprised critically ill patients, who commonly require iMV, and our results may not be applicable to patients outside the ICU. Fifth, we did not have a "gold standard" to confirm that the pathogen identified was responsible for the infection and not only colonizing the airways, a potential limitation particularly for sputum cultures. To limit the number of false positives, we used the most standard quality assessment to accept only lower airway representative samples. Sixth, at the time the current study was conducted, our center did not have routine access to rapid diagnostic methods because they were not standard of care, but these methods have been shown to be promising tools for pathogen identification in HAP [43]. The performance of rapid diagnostic methods in nonventilated HAP, utilizing different sampling strategies, must be evaluated and could produce different results compared to our findings. Particularly, rapid diagnostic methods could increase the sensitivity for pathogen identification in those patients already receiving a new antibiotic upon sample collection, a fact that might explain the reason we achieved only $50 \%$ of microbiological diagnosis using traditional culture methods [44]. Finally, we did not conduct a cost-effective analysis $[1,18]$, which is a key element when comparing different respiratory sampling methods.

\section{Conclusion}

In summary, our study raises the point that a comprehensive approach might be undertaken for microbiological diagnosis in critically ill nonventilated HAP. Sputum determined one third of microbiological diagnosis in HAP patients who were not subsequently intubated. Invasive methods were associated with higher rates of microbiological diagnosis; however, this might be replicated in other populations and through a randomized, well-designed, controlled trial.

\section{Additional files}

\section{Additional file 1: Table S1. Methods for diagnostic approach} Additional data about diagnostic methods stratified by patients with hospital-acquired pneumonia who required or not mechanical ventilation. (PDF $132 \mathrm{~kb}$ )

Additional file 2: Table S2. Comparison between patients who did invasive sampling while receiving or not receiving invasive mechanical ventilation. Additional data about general characteristics and microbiological diagnosis between patients who did invasive sampling methods while receiving or not mechanical ventilation. (PDF $143 \mathrm{~kb}$ )

\section{Abbreviations \\ APACHE II: Acute Physiology and Chronic Health Evaluation II; ATS/ IDSA: American Thoracic Society/Infectious Disease Society of America; BAL: Bronchoalveolar lavage; EAT: Endotracheal aspirate; FBAS: Fiberoptic- bronchoscopy aspirate; HAP: Hospital-acquired pneumonia; HIV: Human immunodeficiency virus infection; ICU: Intensive care unit; iMV: Invasive mechanical ventilation; MDR: Multi-drug resistant; PPM: Potentially pathogenic microorganism; SOFA: Sequential Organ Failure Assessment; VAP: Ventilator-associated pneumonia}

\section{Acknowledgements}

We thank the clinicians and healthcare professionals who helped us to recruit and attend to the cohort.

\section{Funding}

Centro de Investigación Biomedica En Red-Enfermedades Respiratorias (CibeRes). The funding sources had no role in the design and conduct of the study; collection, management, analysis, and interpretation of the data; preparation, review, or approval of the manuscript; and decision to submit the manuscript for publication.

\section{Availability of data and materials \\ The dataset analysed during the current study is available from the corresponding author on reasonable request.}

\section{Authors' contributions}

AT had full access to all the data in the study and takes responsibility for the integrity of the data and the accuracy of the data analysis, including and especially any adverse effects. OTR, TS, FI, AC, and AT were responsible for the study concept and design. OTR, TS, FI, AC, GLB, MF, and AT were responsible for the acquisition, analysis, or interpretation of data. OTR and TS were responsible for the drafting of the manuscript. Fl, AC, GLB, MF, and AT were responsible for the critical revision of the manuscript for important intellectual content. OTR was responsible for the statistical analysis. Fl, AC, $G L B, M F$, and AT were responsible for the administrative, technical, or 
material support. AT was responsible for the study supervision. All authors read and approved the final manuscript.

\section{Ethics approval and consent to participate}

The institution's internal review board approved the study (Comite Etic d'Investigacio Clinica, registry number 2009/5427) and written informed consent was obtained from patients or their next-of-kin.

\section{Consent for publication}

Not applicable.

\section{Competing interests}

The authors declare that they have no competing interests.

\section{Publisher's Note}

Springer Nature remains neutral with regard to jurisdictional claims in published maps and institutional affiliations.

\section{Author details}

${ }^{1}$ Department of Pneumology, Institut Clinic de Respiratori, Hospital Clinic of Barcelona, Institut d'Investigacions Biomèdiques August Pi i Sunyer (IDIBAPS), University of Barcelona (UB), ICREA Academia award, Ciber de Enfermedades Respiratorias (Ciberes, CB06/06/0028), Barcelona, Spain. ${ }^{2}$ Pulmonary Division, Heart Institute (InCor), Hospital das Clinicas HCFMUSP, Faculdade de Medicina, Universidade de Sao Paulo, Sao Paulo, SP, Brazil. ${ }^{3}$ Department of Surgical Sciences and Integrated Diagnostics, IRCCS AOU San Martino- IST, University of Genoa, Genoa, Italy. ${ }^{4}$ Department of Anesthesiology and Intensive Care|, Hospital "A. Gemelli", Catholic University of the Sacred Heart, Rome, Italy. ${ }^{5}$ Seccion Neumologia, Hospital Nacional Prof. Alejandro Posadas, Palomar, Argentina.
\end{abstract}

Received: 20 November 2018 Accepted: 6 February 2019

Published online: 18 February 2019

\section{References}

1. Kalil AC, Metersky ML, Klompas M, Muscedere J, Sweeney DA, Palmer LB, Napolitano LM, O'Grady NP, Bartlett JG, Carratala J, et al. Management of adults with hospital-acquired and ventilator-associated pneumonia: 2016 clinical practice guidelines by the Infectious Diseases Society of America and the American Thoracic Society. Clin Infect Dis. 2016;63(5):e61-e111.

2. Hess D. Guideline for prevention of nosocomial pneumonia and ventilator circuits: time for change? Respir Care. 1994;39(12):1149-53.

3. Torres A, Niederman MS, Chastre J, Ewig S, Fernandez-Vandellos P, Hanberger H, Kollef M, Li Bassi G, Luna CM, Martin-Loeches I, et al. International ERS/ESICM/ESCMID/ALAT guidelines for the management of hospital-acquired pneumonia and ventilator-associated pneumonia: Guidelines for the management of hospital-acquired pneumonia (HAP)/ ventilator-associated pneumonia (VAP) of the European Respiratory Society (ERS), European Society of Intensive Care Medicine (ESICM), European Society of Clinical Microbiology and Infectious Diseases (ESCMID) and Asociacion Latinoamericana del Torax (ALAT). Eur Respir J. 2017;50(3): 1700582.

4. Craven DE, Palladino R, McQuillen DP. Healthcare-associated pneumonia in adults: management principles to improve outcomes. Infect Dis Clin N Am. 2004;18(4):939-62.

5. American Thoracic Society, Infectious Diseases Society of America. Guidelines for the management of adults with hospital-acquired, ventilatorassociated, and healthcare-associated pneumonia. Am J Respir Crit Care Med. 2005;171(4):388-416.

6. Ibn Saied W, Mourvillier B, Cohen Y, Ruckly S, Reignier J, Marcotte G, Siami S, Bouadma L, Darmon M, de Montmollin E, et al. A comparison of the mortality risk associated with ventilator-acquired bacterial pneumonia and nonventilator ICU-acquired bacterial pneumonia. Crit Care Med. 2018. https://doi.org/10.1097/CCM.0000000000003553

7. Richards MJ, Edwards JR, Culver DH, Gaynes RP. Nosocomial infections in medical intensive care units in the United States. National Nosocomial Infections Surveillance System. Crit Care Med. 1999;27(5):887-92.

8. Trouillet JL, Chastre J, Vuagnat A, Joly-Guillou ML, Combaux D, Dombret MC, Gibert C. Ventilator-associated pneumonia caused by potentially drug resistant bacteria. Am J Respir Crit Care Med. 1998;157(2):531-9.
9. Rello J, Ausina V, Ricart M, Castella J, Prats G. Impact of previous antimicrobial therapy on the etiology and outcome of ventilator-associated pneumonia. Chest. 1993;104(4):1230-5.

10. George DL, Falk PS, Wunderink RG, Leeper KV Jr, Meduri GU, Steere EL, Corbett CE, Mayhall CG. Epidemiology of ventilator-acquired pneumonia based on protected bronchoscopic sampling. Am J Respir Crit Care Med. 1998;158(6):1839-47.

11. Ewig S, Torres A, El-Ebiary M, Fabregas N, Hernandez C, Gonzalez J, Nicolas $J M$, Soto L. Bacterial colonization patterns in mechanically ventilated patients with traumatic and medical head injury. Incidence, risk factors, and association with ventilator-associated pneumonia. Am J Respir Crit Care Med. 1999;159(1):188-98.

12. Fagon JY, Chastre J, Domart Y, Trouillet JL, Pierre J, Darne C, Gibert C. Nosocomial pneumonia in patients receiving continuous mechanical ventilation. Prospective analysis of 52 episodes with use of a protected specimen brush and quantitative culture techniques. Am Rev Respir Dis. 1989:139(4):877-84.

13. Chastre J, Trouillet JL, Vuagnat A, Joly-Guillou ML, Clavier H, Dombret MC, Gibert C. Nosocomial pneumonia in patients with acute respiratory distress syndrome. Am J Respir Crit Care Med. 1998;157(4 Pt 1):1165-72.

14. National Nosocomial Infections Surveillance (NNIS) System. Intensive Care Antimicrobial Resistance Epidemiology (ICARE) Surveillance Report, data summary from January 1996 through December 1997: a report from the National Nosocomial Infections Surveillance (NNIS) System. Am J Infect Control. 1999;27(3):279-284.

15. Hunter JD. Ventilator associated pneumonia. Postgrad Med J. 2006;82(965):172-8.

16. Messika J, Stoclin A, Bouvard E, Fulgencio JP, Ridel C, Muresan IP, Boffa JJ, Bachmeyer C, Denis M, Gounant $V$, et al. The challenging diagnosis of noncommunity-acquired pneumonia in non-mechanically ventilated subjects: value of microbiological investigation. Respir Care. 2016;61(2):225-34.

17. Russell CD, Koch O, Laurenson IF, O'Shea DT, Sutherland R, Mackintosh CL. Diagnosis and features of hospital-acquired pneumonia: a retrospective cohort study. J Hosp Infect. 2016;92(3):273-9.

18. Herer B, Fuhrman C, Gazevic Z, Cabrit R, Chouaid C. Management of nosocomial pneumonia on a medical ward: a comparative study of outcomes and costs of invasive procedures. Clin Microbiol Infect. 2009;15(2):165-72.

19. Fabregas N, Ewig S, Torres A, El-Ebiary M, Ramirez J, de La Bellacasa JP, Bauer T, Cabello H. Clinical diagnosis of ventilator associated pneumonia revisited: comparative validation using immediate post-mortem lung biopsies. Thorax. 1999;54(10):867-73.

20. Esperatti M, Ferrer M, Theessen A, Liapikou A, Valencia M, Saucedo LM, Zavala E, Welte T, Torres A. Nosocomial pneumonia in the intensive care unit acquired during mechanical ventilation or not. Am J Respir Crit Care Med. 2010;182:1533-9.

21. Knaus WA, Draper EA, Wagner DP, Zimmerman JE. APACHE II: a severity of disease classification system. Crit Care Med. 1985;13(10):818-29.

22. Vincent JL, Moreno R, Takala J, Willatts S, De Mendonca A, Bruining H, Reinhart CK, Suter PM, Thijs LG. The SOFA (Sepsis-related organ failure assessment) score to describe organ dysfunction/failure. On behalf of the Working Group on Sepsis-Related Problems of the European Society of Intensive Care Medicine. Intensive Care Med. 1996;22(7):707-10.

23. Ferrer M, Difrancesco LF, Liapikou A, Rinaudo M, Carbonara M, Li Bassi G, Gabarrus A, Torres A. Polymicrobial intensive care unit-acquired pneumonia: prevalence, microbiology and outcome. Crit Care. 2015;19:450.

24. Magiorakos AP, Srinivasan A, Carey RB, Carmeli Y, Falagas ME, Giske CG, Harbarth S, Hindler JF, Kahlmeter G, Olsson-Liljequist B, et al. Multidrugresistant, extensively drug-resistant and pandrug-resistant bacteria: an international expert proposal for interim standard definitions for acquired resistance. Clin Microbiol Infect. 2012;18(3):268-81.

25. Weiss E, Zahar JR, Lesprit P, Ruppe E, Leone M, Chastre J, Lucet JC, PaugamBurtz C, Brun-Buisson C, Timsit JF, et al. Elaboration of a consensual definition of de-escalation allowing a ranking of beta-lactams. Clin Microbiol Infect. 2015;21(7):649 e641-10.

26. Leone M, Bechis C, Baumstarck K, Lefrant JY, Albanese J, Jaber S, Lepape A, Constantin JM, Papazian L, Bruder N, et al. De-escalation versus continuation of empirical antimicrobial treatment in severe sepsis: a multicenter nonblinded randomized noninferiority trial. Intensive Care Med. 2014;40(10): 1399-408.

27. Trupka T, Fisher K, Micek ST, Juang P, Kollef MH. Enhanced antimicrobial deescalation for pneumonia in mechanically ventilated patients: a cross-over study. Crit Care. 2017;21(1):180. 
28. Talbot GH. Evolution and current status of United States Food and Drug Administration and European Medicines Agency regulatory guidance for studies of nosocomial pneumonia. Curr Opin Crit Care. 2018;24(5):379-84.

29. Torres A. ICU-acquired pneumonia: is it time to use this term? Curr Opin Crit Care. 2018;24(5):323-4.

30. Meduri GU, Mauldin GL, Wunderink RG, Leeper KV Jr, Jones CB, Tolley E, Mayhall G. Causes of fever and pulmonary densities in patients with clinical manifestations of ventilator-associated pneumonia. Chest. 1994;106:221-35.

31. Giunta V, Ferrer M, Esperatti M, Ranzani OT, Saucedo LM, Li Bassi G, Blasi F, Torres A. ICU-acquired pneumonia with or without etiologic diagnosis: a comparison of outcomes. Crit Care Med. 2013:41(9):2133-43.

32. McCauley LM, Webb BJ, Sorensen J, Dean NC. Use of tracheal aspirate culture in newly intubated patients with community-onset pneumonia. Ann Am Thorac Soc. 2016;13(3):376-81.

33. Prina E, Ranzani OT, Torres A. Community-acquired pneumonia. Lancet. 2015;386(9998):1097-108.

34. Korkmaz Ekren P, Basarik Aydogan B, Gurgun A, Tasbakan MS, Bacakoglu F, Nava S. Can fiberoptic bronchoscopy be applied to critically ill patients treated with noninvasive ventilation for acute respiratory distress syndrome? Prospective observational study. BMC Pulm Med. 2016;16(1):89.

35. Lacroix G, Prunet B, Bordes J, Cabon-Asencio N, Asencio Y, Gaillard T, Pons S, D'Aranda E, Kerebel D, Meaudre E, et al. Evaluation of early minibronchoalveolar lavage in the diagnosis of health care-associated pneumonia: a prospective study. Crit Care. 2013;17(1):R24.

36. Baumann HJ, Klose H, Simon M, Ghadban T, Braune SA, Hennigs JK, Kluge S. Fiber optic bronchoscopy in patients with acute hypoxemic respiratory failure requiring noninvasive ventilation-a feasibility study. Crit Care. 2011; 15(4):R179.

37. Scala R, Naldi M, Maccari U. Early fiberoptic bronchoscopy during noninvasive ventilation in patients with decompensated chronic obstructive pulmonary disease due to community-acquired-pneumonia. Crit Care. 2010; 14(2):R80.

38. Simon M, Braune S, Frings D, Wiontzek AK, Klose H, Kluge S. High-flow nasal cannula oxygen versus non-invasive ventilation in patients with acute hypoxaemic respiratory failure undergoing flexible bronchoscopy-a prospective randomised trial. Crit Care. 2014;18(6):712.

39. Lucangelo U, Vassallo FG, Marras E, Ferluga M, Beziza E, Comuzzi L, Berlot G, Zin WA. High-flow nasal interface improves oxygenation in patients undergoing bronchoscopy. Crit Care Res Pract. 2012;2012:506382.

40. Azoulay E, Mokart D, Lambert J, Lemiale V, Rabbat A, Kouatchet A, Vincent F, Gruson D, Bruneel F, Epinette-Branche G, et al. Diagnostic strategy for hematology and oncology patients with acute respiratory failure: randomized controlled trial. Am J Respir Crit Care Med. 2010;182(8):1038-46

41. Fagon JY, Chastre J, Hance AJ, Montravers P, Novara A, Gibert C Nosocomial pneumonia in ventilated patients: a cohort study evaluating attributable mortality and hospital stay. Am J Med. 1993;94(3):281-8.

42. Ranzani OT, De Pascale G, Park M. Diagnosis of nonventilated hospitalacquired pneumonia: how much do we know? Curr Opin Crit Care. 2018; 24(5):339-46.

43. Kollef MH, Burnham CD. Ventilator-associated pneumonia: the role of emerging diagnostic technologies. Semin Respir Crit Care Med. 2017;38(3): 253-63

44. Torres A, Lee N, Cilloniz C, Vila J, Van der Eerden M. Laboratory diagnosis of pneumonia in the molecular age. Eur Respir J. 2016;48(6):1764-78.

Ready to submit your research? Choose BMC and benefit from:

- fast, convenient online submission

- thorough peer review by experienced researchers in your field

- rapid publication on acceptance

- support for research data, including large and complex data types

- gold Open Access which fosters wider collaboration and increased citations

- maximum visibility for your research: over $100 \mathrm{M}$ website views per year

At $\mathrm{BMC}$, research is always in progress.

Learn more biomedcentral.com/submissions 